\title{
Our Project
}

\author{
Anna B. Gatdula \\ Colloquy Editor, Co-Chair and Co-Founder of Project Spectrum
}

Writing on behalf of the graduate student members of Project Spectrum, I am excited to present our first colloquy, a shortened representation of the conference proceedings of our first symposium held in Autumn 2018. ${ }^{1}$ Organized as a pre-conference symposium prior to the joint national business meetings of the American Musicological Society and the Society for Music Theory, we titled the event "Diversifying Music Academia: Strengthening the Pipeline." The symposium was well attended-a testament to the commitment to progress in our field of music studies, in the various disciplines we call home, and in the classrooms in which we teach. Project Spectrum started with an intent to mobilize the energies of the individuals speaking up at various panels and roundtables at the national conferences-individuals who were sharing their grievances about the lack of diversity and inclusivity in their academic experiences. Hearing similar stories repeated over and over again, happening to separate individuals, we felt inspired to come together, with a belief that collective effort is more effective than individual action.

It's all in the name: Project Spectrum is an initiative, an ongoing enterprise, to substantively broaden and bolster the spectrum of people who are able to succeed in our fields. One part of our mission is to shift the large-scale culture of North American music academia toward equity by confronting racism, sexism, ableism, xenophobia, homophobia, transphobia, settler-colonialism, and other forms of discrimination and injustice. The other is to bolster community, share resources, and hold space for those academics who are marginalized and historically excluded by the academy. These missions are fundamentally intertwined, and taken together, they serve to diversify and strengthen music academia. Our highest goal is that the project becomes moot-to create a world in which those -isms and -phobias would no longer structure higher education and music academia.

The overall success of that Autumn 2018 symposium was due in large part to the organizing work that began in the summer of 2017. Clifton Boyd had reached out to me and a few other graduate students in his network with an idea for a conference or working group for minoritized scholars to share tangible 


\section{Current Musicology}

takeaways and pragmatic solutions for the "diversity work" in our home institutions. From these beginnings, we solidified faculty support, using the Fall 2017 AMS and SMT conferences as networking opportunities, subtly dropping the Project Spectrum name into the intellectual milieu. ${ }^{2}$ For over a year, we had built up a community in support of our nascent work. We worked to receive grants from the AMS, SMT, SEM, and we worked especially hard to receive the Sphinx Organization's MPower Grant. I remember the group of us graduate student organizers sitting in the UTSA Institute of Texan Cultures before the event officially started. We had registered over a hundred participants, although we anticipated less turnout given the nature of pre-conference commitments. Much to our relief, excitement, and surprise, we filled the lecture room. I remember giving the opening remarks, which included a parochial meet and greet, and the thrill of commotion as people stood up to meet one another in the space we had worked so hard to make real.

For our first conference, we wanted to address the issue of the "pipeline." Social scientists of higher education refer to an individual's academic progressfrom college matriculation to graduation and beyond-as their trajectory through the "educational pipeline." Studying the pipeline centers a systemic, structural analysis of a student's potential advancement through academia. This colloquy attempts to map out existing discussions around inclusion and equity in music academia, with a specific focus on identifying and analyzing the structures in academia that work against minoritized and historically excluded scholars. First off, it is often difficult for underrepresented minoritized folks to enter the pipeline. For me, my entry point to the pipeline started early. I was lucky enough to have access to orchestras and choirs in elementary school; my parents valued my music education and supported me with external music lessons. Moving on to high school, I was privileged to go to a well-funded musical arts program at a public school. My parents assisted me as I pursued music performance in college; then, I went on to benefit from financial support in graduate school. I had (and still have) a really lucky go within this pipeline, and I remain aware of the privilege I have in comparison to the people who were not so lucky. It is difficult for people without points of entry to take up graduate studies in music. Scholars and administrators have been dismissive of this point of entry, often espousing language such as "they aren't interested in classical music because they simply don't commit themselves." This stance is obviously not self-reflexive and obfuscates the decisions that directly discourage a more diverse pool of applicants. 


\section{Project Spectrum Colloquy}

Having gained access to the pipeline, many individuals then face several obstacles and blockages that deter progress through the pipeline. We who identify as underrepresented within the hegemonic social circles of academia experience a sort of fragmentation as we ascend the pipeline. Reaching higher levels of academia, we see fewer and fewer people who look like us, have life experiences like us. For example, ableism inhibits success in academia as it propagates achievement through exceptional individuality. We have each benefited from a pipeline of sorts that has brought each of us to the proverbial "here"; but there are financial, social, and cultural barriers to this pipeline.

Then we arrive at the lucky few who make it through the pipeline to achieve the coveted honorifics of academia's success (a doctorate degree, a tenured position, etc.). We pivot to thinking about gaining power and control over the pipeline. Now, we want to strengthen the pipeline for those who are not here. How can we privileged few alleviate the bottleneck effect of the pipeline? This could mean: making the classroom more inclusive; checking our implicit biases; developing leaders, in our departments and in our discipline, who identify as underrepresented, minoritized, and historically excluded; publishing innovative research that opens doors to similarly-minded new scholars; and building each other up through the trials and tribulations of our precarious job markets. Strengthening the pipeline means each of those things and more. Our contributors offer some initial gestures toward this end. We have attempted to structure the colloquy in a way that reflects the progressive stages of the pipeline.

First, Margaret Thomas takes us into the undergraduate music theory classroom in "Making the Case for Equity Pedagogy." Addressing one of the entry points into the music academia pipeline, Thomas proposes two educational theories to make our classrooms more inclusive: universal design for learning (UDL) and equity pedagogy. More importantly, she calls for music pedagogues to be proactive and to address the structural inequities that shape a student's engagement in and out of the classroom. Thomas's call to music scholars reminds me of bell hooks's call that "part of the luxury and privilege of the role of teacher/professor today is the absence of any requirement that we be self-actualized" $(1994,17)$. Thomas's contribution to the colloquy exemplifies a professor's commitment to self-actualization: she recognizes her own privilege, she foregrounds her students' experiences, and calls for her peers to join her in this honest self-reflection.

Then, Matthew Ovalle and Andrew Dell'Antonio contribute their joint-paper "Mentoring, Institutional Barriers, Structures of Justice: A Dialogue Across Positions of Privilege and Power." I remember them in front of that lecture hall: 


\section{Current Musicology}

they spoke with vulnerability and care from their positions as mentor and mentee, outlining the alternative pathways that give people the chance to make their own way through the pipeline. But most importantly, I remember them sitting together, side-by-side, dismantling the hierarchy of mentorship with their presence in that lecture space. Dell'Antonio writes, "and if we are privileged to be in the system, we have the authority to disrupt it." I would add, shoulder-toshoulder, side-by-side, we will disrupt it. Ovalle writes that he "can really only speak to my experience," but his courageous testimony challenges us from the get-go: "The first thing I want to say is that I do not belong in academia." Many of us do not belong in academia - the pipelines have made it so - and yet so many of us are here. Ovalle's experience reminds us of the allies and friends that allow us to stay here. He shares a story of his own student in need who was skipping class and notes: “I don't always assume that it's because they won't [attend class], but that it's because they can't." Let us remember that for many of us, it's not that we won't get through the pipeline, it's because we can't.

Sarah Hankins follows with thoughts on mental illness, arguing that it is a gap in our discourse, a gap that is initially discussed in Ovalle's testimony. Hankins asks us to bear witness to experiences of those who boldly declare that they are "unfit" for the pipeline- "unfit" to survive the pipeline, to have access to the pipeline, and for the so-called promises at the end of the pipeline. Following the work of Black studies, queer of color critique, Black radicalism, Afropessimism, and especially the writings of Stefano Harney and Fred Moten, Hankins invites us to the "Undercommons," a collective of those who declare: I am unfit. To which the response is simply: We agree. The Undercommons asks us to attend to the blockages in the pipeline-and then to stay there, to refuse subjection into the normative flow of the pipeline, to demand attention to our aches and pain, and to do it all as a collective. Hankins's intervention in this colloquy demands pause in academia's system of perpetual motion.

Finally, Tekla Babyak asks us to re-imagine what is on the other side of the pipeline. In her colloquy contribution, she shares her advocacy experience in fighting for both independent scholars' and disabled scholars' seat at the proverbial table. She imagines an academic discipline that would readily accept, acknowledge, and uplift independent scholars-instead of considering them half- or failed scholars for their lack of institutional affiliation. And she imagines an academic discipline that would readily include disabled scholars, not for their exceptionality in achieving scholarship, but for their ability to contribute to a more diverse and inclusive intellectual milieu. She critiques the ableism endemic to the academic pipeline, an ableism that veils the physical and-if I might add- 
emotional, mental, and spiritual obstructions in our discipline's path to so-called success.

All in all, our contributors ask us not only how we can strengthen the pipeline but also what to look for on the other side of that pipeline. They begin to provide glimpses of the world we want to build - an academic world committed to equity, to care, to a sense that the world is in fact ours and ours to share with our students, our colleagues, and our (fully actualized) selves. As bell hooks writes:

To commit ourselves to the work of transforming the academy so that it will be a place where cultural diversity informs every aspect of our learning, we must embrace struggle and sacrifice. We cannot be easily discouraged. We cannot despair when there is conflict. Our solidarity must be affirmed by shared belief in a spirit of intellectual openness that celebrates diversity, welcomes dissent, and rejoices in collective dedication to truth. (1994, 33)

As the tides change, our pipelines have to withstand the new currents. And although it's sink or swim, it's up to us to strengthen these pipelines.

Notes

${ }^{1}$ Thank you to my fellow graduate student organizers for the 2018 symposium: Clifton Boyd, Catrina Kim, Laurie Lee, Lissa Reed, M. Leslie Santana. Special shoutout to the new graduate student organizers who have joined us: Carlota Aguilar, Hyeonjin Park, and Toru Momii. To follow Project Spectrum's ongoing work, please see our website:

https://projectspectrummusic.com

2 Thank you to our original faculty affiliate members: Eduardo Herrera, Ellie M. Hisama, Tammy L. Kernodle, Matthew D. Morrison, and Joseph Straus.

References

hooks, bell. 1994. Teaching to Transgress: Education as the Practice of Freedom. New York: Routledge. 